\title{
Histological and immunohistochemical characterization of feline renal cell carcinoma: a case series
}

\author{
Federico BONSEMBIANTE ${ }^{1}$, Silvia Lucia BENALI ${ }^{1)}$, Davide TREZ ${ }^{1)}$, Luca ARESU $^{1)}$ and Maria Elena GELAIN ${ }^{1) *}$ \\ ${ }^{1)}$ Department of Comparative Biomedicine and Food Science, University of Padua, Viale dell'Università 16, 35020, Agripolis, Legnaro (PD), \\ Italy
}

(Received 9 December 2015/Accepted 5 February 2016/Published online in J-STAGE 18 February 2016)

ABSTRACT. Four feline renal cell carcinomas (RCCs) were examined using histopathological and immunohistochemical procedures. Specimens were classified by predominant histological pattern according to WHO criteria. A panel of antibodies including $\beta$-catenin, C-KIT, VEGF and VEGF-R2 and double immunostaining for vimentin/cytokeratin and for E-cadherin/CD10 was selected to characterize the tumors. Neoplasms were classified as tubular (3/4) and papillary (1/4). Neoplastic epithelial cells were cytokeratin, vimentin, E-cadherin, VEGF-R2 positive and C-KIT negative; 3 cases were $\beta$-catenin positive, whereas only 2 tumors were CD10 and VEGF positive. No correlation with histotype was evident. Our results confirm the low frequency of RCCs in cats and suggest a histological pattern similar to canine RCCs. In contrast, a peculiar immunohistochemical profile different from both canine and human RCCs is identified.

KEY WORDS: cat, immunohistochemistry, renal cell carcinoma

doi: 10.1292/jvms.15-0697; J. Vet. Med. Sci. 78(6): 1039-1043, 2016

The prevalence of primary renal tumors (RT) in domestic animals is less than $1 \%$ of the total neoplasms reported. Except for lymphoma, other primary RT in cats are extremely rare [27] and only few case reports [13, 27], and surveys of feline tumors [15] are described. Based on the data available, feline renal cell carcinomas (RCCs) show no breed predilection, occur in older cats, unilaterally, and metastasize sporadically [27].

In dogs, RT account for $0.6-1.7 \%$ of neoplasms, and RCC is the most frequent subtype, accounting for $60-85 \%$ [23] and being more common in male middle-aged dogs without breed predilection [4]. RCCs are classified on the predominant histologic pattern, like papillary, tubular or solid [12], but a mixture of all types is often present [23]. These histologic types can be further classified as chromophobic, eosinophilic or clear cell variants, and generally, all the 3 cell types are present [12]. Immunohistochemical features of RCCs were extensively analyzed only in dogs. No correlation between immunohistochemical profile and biological behavior was found [12], but mitotic index was identified as the best predictor of survival $[9,12]$. In human, more than $90 \%$ of the RT arise from the renal tubules [29], and RCC is the most common one, representing approximately $2-3 \%$ of all cancers worldwide [1] and is classified into 8 different histological subtypes [29].

The diagnosis is usually based on morphological analysis; however, ancillary techniques, such as immunohistochemis-

\footnotetext{
*Correspondence to: Gelain, M.E., Dipl ECVCP, Department of Comparative Biomedicine and Food Science, University of Padua. AGRIPOLIS - Viale dell'Università 16, 35020, Agripolis, Legnaro (PD), Italy. e-mail: mariaelena.gelain@unipd.it

(C2016 The Japanese Society of Veterinary Science

This is an open-access article distributed under the terms of the Creative Commons Attribution Non-Commercial No Derivatives (by-nc-nd) License $<$ http://creativecommons.org/licenses/by-nc-nd/4.0/>.
}

try, electron microscopy, cytogenetics and molecular genetics, have proved to be useful in refining RCCs classification and offer biological data [28]. Some studies have also suggested the use of immunohistochemistry in combination with histopathology to define RCCs origin and classification, to differentiate renal cell neoplasms from non-renal tumors and to correctly identify metastatic RCCs in distant organs, especially when only small biopsy specimens are available [20, 29].

The purposes of this study are to describe the histological features and the immunohistochemical profile in four feline RCCs and to evaluate a possible correlation between histologic pattern and immunohistochemical profile.

Four cases of RCC diagnosed between October 2005 and February 2014 were retrieved from the archive of the Histopathology Services, Department of Comparative Biomedicine and Food Science, University of Padua. All specimens were obtained by nephrectomy. Tumor samples were fixed in $10 \%$ neutral buffered formalin and processed routinely. Serial $3 \mu \mathrm{m}$ thick sections for each tumor were stained with hematoxylin-eosin and Periodic Acid Schiff (PAS). The specimens were evaluated by light microscopy for the diagnoses of RCC. Tumors were classified by predominant histologic pattern according to World Health Organization (WHO) criteria [23]. The presence or absence of necrosis, nuclear pleomorphism (slight to marked) and mitotic index (mitotic figures per 10 high-power fields) were also scored. Regional lymph nodes were not available for evaluation.

For immunohistochemistry (IHC), serial paraffin sections were processed as previously described [30] using an automatic immunostainer (Ventana Benchmark XT, Ventana Medical Systems Inc., Tucson, AZ, U.S.A.).

All the antibodies (Abs) used in this work were previously tested in cat $[7,18,24,25,30]$. The following markers were assessed by IHC: cytokeratins (CKs), vimentin (VIM), CD10, E-cadherin (E-CAD), $\beta$-catenin ( $\beta$-CAT), C-KIT, 


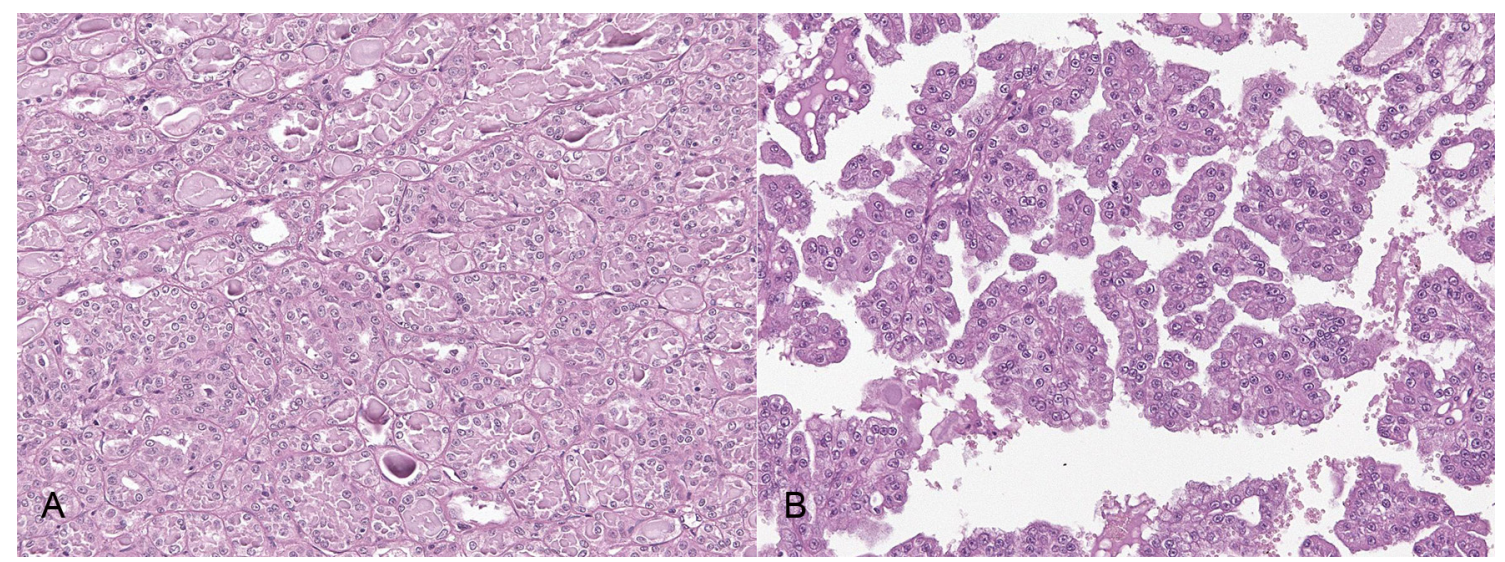

Fig. 1. Histological features of tubular and papillary RCCs. A) tubular RCC: neoplastic cells were arranged in monolayer forming irregular tubules often distended by intraluminal homogenous, eosinophilic material (proteinaceous material) and separated by variably thickened septa of fibrovascular stroma. Anisocytosis and anisokaryosis were moderate. 200× magnification, Hematoxylin and eosin (HE). B) papillary RCC: neoplastic cells formed irregular papillae or tubular structures associated with moderate fibrovascular stroma. Anisocytosis and anisokaryosis were moderate. 200× magnification, HE.

Table 1. Histologic and Immunohistochemical features of 4 feline Renal Cell Carcinomas and normal feline kidney

\begin{tabular}{|c|c|c|c|c|c|c|c|c|c|c|}
\hline No. & Histologic Pattern & Mitotic index & Vim & panCK & CD10 & E-cad & $\beta$-cat & c-KIT & VEGF & VEGF-R2 \\
\hline 1 & RCC tubular & 5/10HPF & ++ & + & - & + & - & - & - & + \\
\hline 2 & RCC tubular & 4/10HPF & + & + & - & + & + & - & - & + \\
\hline 3 & RCC tubular & 4/10HPF & ++ & + & + & ++ & ++ & - & + & + \\
\hline 4 & RCC papillary & 5/10HPF & + & + & + & ++ & ++ & - & + & + \\
\hline Control & Proximal tubule & & - & + & + & - & + & - & $+1-$ & - \\
\hline Control & Distal tubule & & - & + & - & + & + & - & $+/-$ & - \\
\hline Control & Glomerulus & & + a) & -a) & + a) & -a) & _a) & -a) & -a) & -a) \\
\hline
\end{tabular}

Scoring: -, negative; +/-, weak; +, moderate; ++, strong. a) Positivity to VIM is detected in endothelial glomerular cells, while positivity to CD10 is at the urinary pole of the Bowman's capsule. All the other glomerular cells showed negative for the other markers. Mitotic index : mitotic figures per 10 high-power fields (HPF).

vascular endothelial growth factor (VEGF) and vascular endothelial growth factor receptor 2 (VEGF-R2). Double immunolabelings (using DAB and Red detection kit) for VIM/ $\mathrm{CKs}$ and for E-CAD/CD10 were also performed to evaluate the co-expression of these antigens. The same Abs panel was employed in normal renal samples to define the IHC profile. The immunoreactivity for each marker was assessed semiquantitatively (Table 1). In Table S1 are reported sources, clones and dilution for each antibody.

All the cats described in this report were male, ranged from 9 to 12 years (median age: 10.5 years). The referring veterinarians reported no other neoplastic lesions identified during clinical examination. The tumors were classified as tubular $(n=3)$ and papillary $(n=1)$ RCCs.

In tubular RCCs, neoplastic cells were arranged in monolayer forming irregular tubules often distended by intraluminal homogenous, eosinophilic, PAS-positive material. Focally, cells were arranged in multilayer lining papillae with fibrovascular core. Cells were $30-40 \mu \mathrm{m}$ in size, cuboidal to columnar, with indistinct cell borders and moderate amount of eosinophilic amorphous cytoplasm. Nuclei were round to oval, 25-30 $\mu \mathrm{m}$, centrally located with marginated chromatin and prominent, single round nucleolus. Anisocytosis and anisokaryosis were moderate. Mitoses were 4 to 5 per 10 higher-power fields (HPF) (Fig. 1A).

The papillary RCC was poorly defined and composed of neoplastic cells lining irregular papillae or tubular structures associated with moderate fibrovascular stroma. Neoplastic cells were columnar to polygonal, with indistinct cell borders and moderate eosinophilic cytoplasm. Nuclei were round, central, with granular chromatin and single, prominent nucleolus. Anisocytosis and anisokaryosis were moderate. Multifocal necrotic areas with mineralizations and moderate neutrophilic inflammation were present. Adjacent renal tissue was compressed with moderate glomerular and tubular atrophy. Mitoses were 5 per 10 HPF (Fig. 1B).

Table 1 shows immunohistochemistry results. In normal kidney, VIM was detected in endothelial glomerular cells, while cells at the urinary pole of the Bowman's capsule were CD10 positive. All the other glomerular cells were completely negative. Proximal and distal tubular epithelial cells (TECs) expressed CKs and $\beta$-CAT. Moreover, proximal TECs were positive for CD10 and negative for E-CAD, and vice versa, distal TECs were positive for E-CAD and negative for CD10 (Fig. 2 A-C). C-KIT was detected neither in glomerular nor in TECs. 


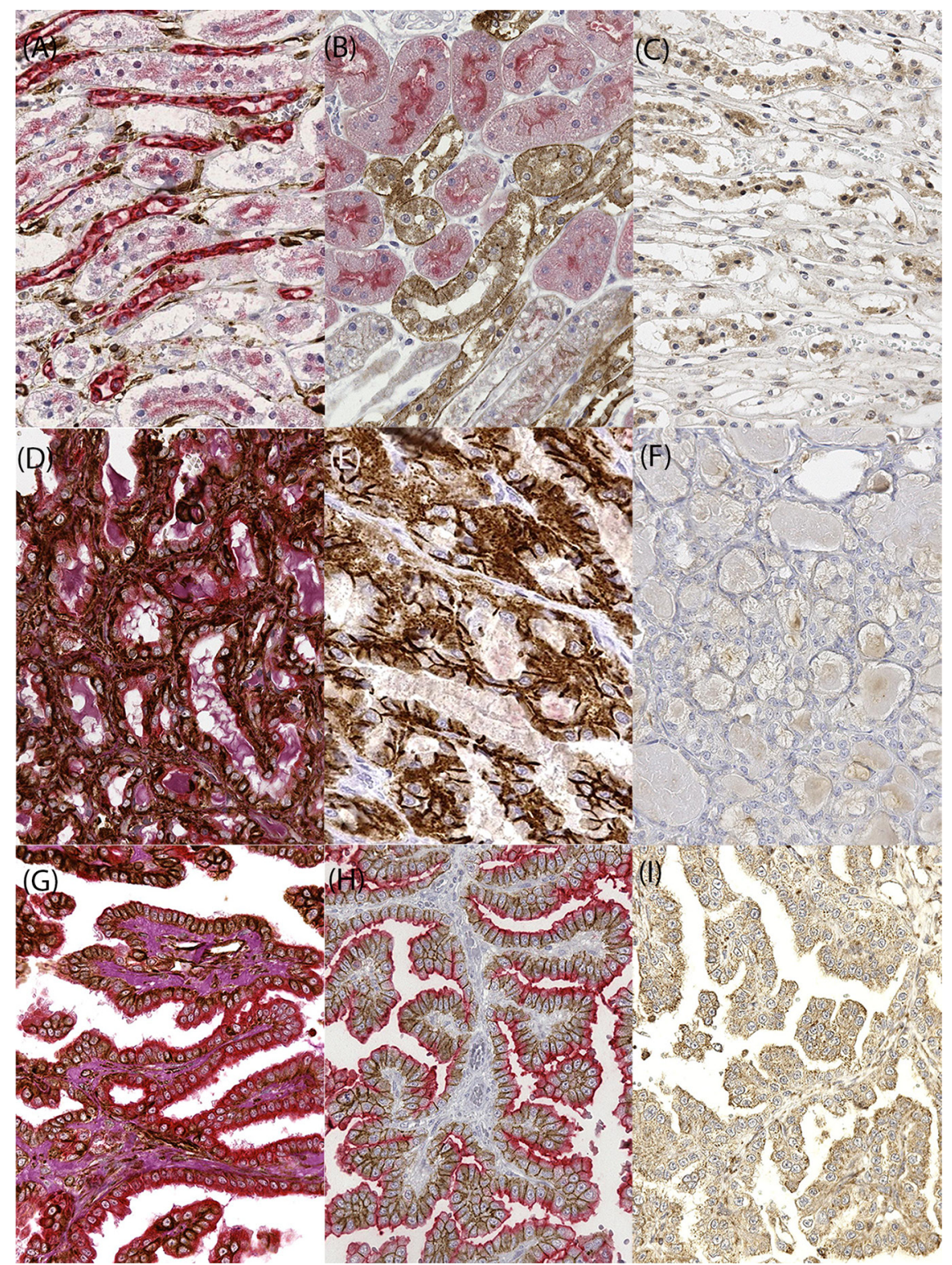

Fig. 2. Immunohistochemical results in normal kidney and in neoplastic samples. A) normal kidney, double IHC VIM (brown) /CK (red): proximal and distal tubular epithelial cells were positive for panCK. B) normal kidney, double IHC E-CAD (brown)/CD10 (red): proximal tubular ECs were positive for $\mathrm{CD} 10$ and negative for E-CAD, and opposite pattern expression was present on distal tubular ECs. C) normal kidney, IHC VEGF (brown). Low expression was evident on tubular epithelial cells. D) RCC tubular, double IHC VIM (brown)/CK (red): neoplastic cells were positive for CK and VIM. The positivity to these markers was always localized in the cytoplasm. E) RCC tubular, double IHC E-CAD (brown)/CD10 (red): the expression of E-CAD on the membrane and the negativity to CD10 could reflect the distal tubule origin of the neoplasm. F) RCC tubular, IHC VEGF (brown). No expression was evident on neoplastic cells. G) RCC papillary, double IHC VIM (brown)/CK (red). H) RCC papillary, double IHC E-CAD (brown)/CD10 (red). I) RCC papillary, IHC VEGF (brown). A strong and diffuse immunoreactivity for VIM, CK, E-CAD and CD10 was evident on neoplastic cells. Also, VEGF showed higher expression compared to normal kidney. Double immunostaining for CK and vimentin and counterstaining with Periodic Acid Schiff (PAS); Double immunostaining for CD10 and E-CAD, single immunostaining for VEGF and counterstaining with hematoxylin. 400× magnification.

All the RCCs were positive for CKs, VIM and E-CAD. Neoplastic ECs in 2 tumors were CD10 positive, while positivity to $\beta$-CAT was recorded in neoplastic ECs in 3 tumors, but without nuclear positivity. VEGF-R2 was expressed by ECs in all tumor samples, whereas VEGF was expressed only in 2 cases. None of the specimens expressed C-KIT. Double IHC analysis showed for all the cases the co-expression of VIM and CKs within neoplastic ECs, whereas co-expression of E-CAD and CD10 was detected in 2 cases and the other 2 were E-CAD positive and CD10 negative (Fig. 2 D-I). 
Table 2. Immunoprofile of the major renal neoplasms in human and dogs [26, 28, 29] compared to results obtained on 4 cases of feline renal cell carcinoma

\begin{tabular}{|c|c|c|c|c|c|c|c|c|}
\hline & $\begin{array}{l}\text { Human clear } \\
\text { cell }\end{array}$ & $\begin{array}{l}\text { Human } \\
\text { papillary }\end{array}$ & $\begin{array}{c}\text { Human } \\
\text { chromophobe }\end{array}$ & $\begin{array}{l}\text { Canine tubular- } \\
\text { papillary }(n=3)\end{array}$ & $\begin{array}{l}\text { Canine papillary } \\
\qquad(\mathrm{n}=4)\end{array}$ & $\begin{array}{l}\text { Canine solid } \\
\qquad(\mathrm{n}=3)\end{array}$ & $\begin{array}{l}\text { Feline tubular } \\
(\mathrm{n}=3)\end{array}$ & $\begin{array}{c}\text { Feline papillary } \\
(\mathrm{n}=1)\end{array}$ \\
\hline panCk & $\begin{array}{c}+ \\
(\mathrm{CK} 8, \mathrm{CK} 18)\end{array}$ & $\begin{array}{c}+ \\
(\mathrm{CK} 7, \mathrm{CK} 8, \mathrm{CK} 18)\end{array}$ & + & $+/-$ & $+/-$ & - & + & + \\
\hline Vimentin & + & + & - & + & $+/-$ & + & + & + \\
\hline $\mathrm{CD} 10$ & + & + & $+/-$ & $+/-$ & - & $+/-$ & $+/-$ & + \\
\hline E-cadherin & $+1-$ & + & + & nd & nd & nd & + & + \\
\hline C-kit & $+1-$ & $+/-$ & + & + & + & + & - & - \\
\hline
\end{tabular}

Scoring: -, negative; +/-, weak; +, moderate; ++, strong. nd: not determined.

In this case series, the histological and immunohistochemical features of a small series of feline RCCs are described. Our results identify the co-expression of CKs and VIM and no expression of C-KIT as a common finding in all the RCCs. However, no correlation with histotype was clearly evident.

RCCs are rare in cats, as confirmed by the small number of cases in our database including approximately 11,000 cases in a spanning period of 9 years. Tubular RCC is considered the most common variety in domestic animals. However, recently, solid and papillary were reported to be the predominant subtypes in dogs $[9,12]$. In our study, tubular subtype was seen in 3 out of 4 of the tumors, and except for sample 1, all tumors had a mixture of histologic pattern, in accordance with previous reports [23]. All tumors showed low mitotic index and slight to moderate nuclear atypia. Apparently, this morphology is suggestive of low-grade neoplasms, but unfortunately, the lack of follow-up data prevents any correlation with biological behavior.

There is a paucity of literature on feline RCC, particularly focusing on protein expression profile. We included in our panel five antibodies (CKs, VIM, CD10, E-CAD and C-KIT) which are used in human medicine as a helpful combination for the diagnosis and classification of $\operatorname{RCC}[2,5]$.

All tumors co-expressed VIM and CKs, while in normal kidney, these markers were differently expressed in the nephron, with endothelial cells positive to VIM and tubular cells positive to CKs. These findings are similar with those previously reported in human in which co-expression of these molecules is widely known in RCCs, particularly tubulopapillary and clear cell subtypes. In contrast, this phenotype was recorded occasionally in canine RCCs [12] (Table 2). Some authors proposed that VIM and CKs expression by ECs demonstrates the origin from remnants of embryonic mesenchyme [14], but could also be associated with undifferentiated renal stem cells or an acquired epithelial-mesenchymal transition (EMT) associated with an invasive phenotype [8]. The co-expression of the two proteins in TECs was reported during EMT in chronic renal damage [3] and interpreted as an intermediate step in this process [6]. However, during EMT, co-localization was seen in scattered cells [6], whereas in feline RCCs, the majority of the cells co-express VIM and CKs. Indeed, this might be considered a critical step in the neoplastic process already described in other feline tumors, such as skin adnexal, thyroid, pulmonary and mammary carcinomas $[21,22]$. Also, this immunohistochemical profile might be useful to differentiate RCCs from unknown primary cancer localized in the kidney. C-KIT, a transmembrane tyrosine kinase growth factor [11], is commonly used to identify chromophobe RCC and oncocytoma in human [29], however none of our tumors expressed this protein, being more similar to human clear cell and papillary RCCs [19]. This also differentiates from dog where C-KIT is expressed in the majority of the RCCs [12].

E-CAD in normal human kidney is expressed in renal tubular cells, and the kidney specific isoform is expressed exclusively in the renal distal convoluted and collecting duct cells [29]; instead, CD10 is detected on brush border of proximal convoluted tubule [17]. In our study, double IHC analysis confirmed this pattern in feline kidney. In human medicine, RCCs with proximal tubular differentiation express CD10, whereas those with distal tubular differentiation express kidney-specific cadherin. Additionally, it has been proposed that, while conventional RCCs are closely related to mature proximal ECs, papillary subtype is more similar to embryonal proximal tubular cells [16]. In our cases, 2 tubular RCCs were E-CAD positive and CD10 negative, confirming the distal convoluted tubule origin. The other 2 cases expressed both E-CAD and CD10: if we could assume an embryonal proximal tubular cells origin for papillary RCCs, we could not identify the tubular segment of origin for the tubular ones. Moreover, the use of a monoclonal antibody against E-CAD, a molecule expressed in several different subtypes of RCC [29], limits the possibility to correctly define the origin of the neoplasm.

VEGF and its receptors are essential in physiological and pathological angiogenesis by stimulating endothelial cells to form new vessels [10]. In our study, normal kidney was negative to VEGF-R2 and slightly positive to VEGF, determining a low angiogenic activity. On the contrary, the expression of VEGF-R2 was total in our samples and variable for VEGF. This could reflect a variable angiogenic activity among tumor.

In conclusion, we confirm the low frequency of feline RCCs. Furthermore, even if restricted by the low number of cases, feline RCC seems to have an histological pattern similar to canine RCC, but a different immunohistochemical profile compared to human and canine RCC. In particular, the co-expression of VIM and CKs and the negativity to CKIT could be useful in the diagnostic approach to feline RT. 
However, the small number of cases included and the lack of clinical information are a limitation, and studies, including clinical data, are necessary to define the prognostic significance of histological and immunophenotypical features.

Declaration of Conflicting Interest. The Authors declare that there is no conflict of interest.

\section{REFERENCES}

1. Ahluwalia, P., Nair, B. and Kumar, G. 2013. Renal Cell Carcinoma Associated with Xp11.2 Translocation/TFE3 Gene Fusion: A Rare Case Report with Review of the Literature. Case Rep. Urol. 2013: 810590. [Medline]

2. Allory, Y., Bazille, C., Vieillefond, A., Molinié, V., CochandPriollet, B., Cussenot, O., Callard, P. and Sibony, M. 2008. Profiling and classification tree applied to renal epithelial tumours. Histopathology 52: 158-166. [Medline]

3. Aresu, L., Rastaldi, M. P., Scanziani, E., Baily, J., Radaelli, E., Pregel, P. and Valenza, F. 2007. Epithelial-mesenchymal transition (EMT) of renal tubular cells in canine glomerulonephritis. Virchows Arch. 451: 937-942. [Medline] [CrossRef]

4. Baskin, G. B. and De Paoli, A. 1977. Primary renal neoplasms of the dog. Vet. Pathol. 14: 591-605. [Medline]

5. Bazille, C., Allory, Y., Molinié, V., Vieillefond, A., Cochand-Priollet, B., Cussenot, O., Callard, P. and Sibony, M. 2004. [Immunohistochemical characterisation of the main histologic subtypes of epithelial renal tumours on tissue-microarrays. Study of 310 cases]. Ann. Pathol. 24: 395-406. [Medline] [CrossRef]

6. Benali, S. L., Lees, G. E., Castagnaro, M. and Aresu, L. 2014. Epithelial mesenchymal transition in the progression of renal disease in dogs. Histol. Histopathol. 29: 1409-1414. [Medline]

7. Cavicchioli, L., Ferro, S., Callegari, C., Auriemma, E., Zini, E. and Zappulli, V. 2013. Carcinosarcoma of the biliary system in a cat. J. Vet. Diagn. Invest. 25: 562-565. [Medline] [CrossRef]

8. Cervantes-Arias, A., Pang, L. Y. and Argyle, D. J. 2013. Epithelial-mesenchymal transition as a fundamental mechanism underlying the cancer phenotype. Vet. Comp. Oncol. 11: 169-184. [Medline] [CrossRef]

9. Edmondson, E. F., Hess, A. M. and Powers, B. E. 2015. Prognostic significance of histologic features in canine renal cell carcinomas: 70 nephrectomies. Vet. Pathol. 52: 260-268. [Medline] [CrossRef]

10. Fox, S. B., Turley, H., Cheale, M., Blázquez, C., Roberts, H., James, N., Cook, N., Harris, A. and Gatter, K. 2004. Phosphorylated KDR is expressed in the neoplastic and stromal elements of human renal tumours and shuttles from cell membrane to nucleus. J. Pathol. 202: 313-320. [Medline] [CrossRef]

11. Gil da Costa, R. M., Matos, E., Rema, A., Lopes, C., Pires, M. A. and Gärtner, F. 2007. CD117 immunoexpression in canine mast cell tumours: correlations with pathological variables and proliferation markers. BMC Vet. Res. 3: 19. [Medline] [CrossRef]

12. Gil da Costa, R. M., Oliveira, J. P., Saraiva, A. L., Seixas, F., Faria, F., Gärtner, F., Pires, M. A. and Lopes, C. 2011. Immunohistochemical characterization of 13 canine renal cell carcinomas. Vet. Pathol. 48: 427-432. [Medline] [CrossRef]

13. Gómez Selgas, A., Scase, T. J. and Foale, R. D. 2014. Unilateral squamous cell carcinoma of the renal pelvis with hydronephrosis in a cat. J. Feline Med. Surg. 16: 183-188. [Medline] [CrossRef]

14. Grieco, V., Riccardi, E., Rondena, M., Romussi, S., Stefanello, D. and Finazzi, M. 2006. The distribution of oestrogen receptors in normal, hyperplastic and neoplastic canine prostate, as dem- onstrated immunohistochemically. J. Comp. Pathol. 135: 11-16. [Medline] [CrossRef]

15. Henry, C. J., Turnquist, S. E., Smith, A., Graham, J. C., Thamm, D. H., O'Brien, M. and Clifford, C. A. 1999. Primary renal tumours in cats: 19 cases (1992-1998). J. Feline Med. Surg. 1: 165-170. [Medline] [CrossRef]

16. Herrera, G. A. and Turbat-Herrera, E. A. 2014. Ancillary diagnostic techniques in the evaluation of adult epithelial renal neoplasms: indications, caveats, and pitfalls. Appl. Immunohistochem. Mol. Morphol. 22: 77-98. [Medline] [CrossRef]

17. Holm-Nielsen, P. and Pallesen, G. 1988. Expression of segmentspecific antigens in the human nephron and in renal epithelial tumors. APMIS Suppl. 4: 48-55.

18. Islam, M. S., Matsumoto, M., Hidaka, R., Miyoshi, N. and Yasuda, N. 2012. Expression of NOS and VEGF in feline mammary tumours and their correlation with angiogenesis. Vet. $J$. 192: 338-344. [Medline] [CrossRef]

19. Krüger, S., Sotlar, K., Kausch, I. and Horny, H. P. 2005. Expression of KIT (CD117) in renal cell carcinoma and renal oncocytoma. Oncology 68: 269-275. [Medline] [CrossRef]

20. Lopez-Beltran, A., Scarpelli, M., Montironi, R. and Kirkali, Z. 2006. 2004 WHO classification of the renal tumors of the adults. Eur. Urol. 49: 798-805. [Medline] [CrossRef]

21. Martín de las Mulas, J., Espinosa de los Monteros, A., Carrasco, L., van Niel, M. and Fernández, A. 1995. Immunohistochemical distribution pattern of intermediate filament proteins in 50 feline neoplasms. Vet. Pathol. 32: 692-701. [Medline] [CrossRef]

22. Martín de las Mulas, J., Espinosa de los Monteros, A., Bautista, M. J., Gómez-Villamandos, J. C. and Morales, C. 1994. Immunohistochemical distribution pattern of intermediate filament proteins and muscle actin in feline and human mammary carcinomas. J. Comp. Pathol. 111: 365-381. [Medline] [CrossRef]

23. Meuten, D. J., Everitt, J., Inskeep, W., Jacobs, R. M., Peleteiro, M. and Thompson, K. G. 2004. Renal tumors. pp. 14-20. In. WHO histological classification of tumors of the urinary system of domestic animals, 2nd series, vol. 11. Armed Forces Institute of Pathology, Washington, DC.

24. Morini, M., Gentilini, F., Pietra, M., Spadari, A., Turba, M. E., Mandrioli, L. and Bettini, G. 2011. Cytological, immunohistochemical and mutational analysis of a gastric gastrointestinal stromal tumour in a cat. J. Comp. Pathol. 145: 152-157. [Medline] [CrossRef]

25. Rodriguez-Cariño, C., Fondevila, D., Segalés, J. and Rabanal, R. M. 2009. Expression of KIT receptor in feline cutaneous mast cell tumors. Vet. Pathol. 46: 878-883. [Medline] [CrossRef]

26. Skinnider, B. F. and Amin, M. B. 2005. An immunohistochemical approach to the differential diagnosis of renal tumors. Semin. Diagn. Pathol. 22: 51-68. [Medline] [CrossRef]

27. Steinberg, H. and Thomson, J. 1994. Bilateral renal carcinoma in a cat. Vet. Pathol. 31: 704-705. [Medline] [CrossRef]

28. Tan, P. H., Cheng, L., Rioux-Leclercq, N., Merino, M. J., Netto, G., Reuter, V. E., Shen, S. S., Grignon, D. J., Montironi, R., Egevad, L., Srigley, J. R., Delahunt, B., Moch H., ISUP Renal Tumor Panel 2013. Renal tumors: diagnostic and prognostic biomarkers. Am. J. Surg. Pathol. 37: 1518-1531. [Medline] [CrossRef]

29. Truong, L. D. and Shen, S. S. 2011. Immunohistochemical diagnosis of renal neoplasms. Arch. Pathol. Lab. Med. 135: 92-109. [Medline]

30. Zappulli, V., De Cecco, S., Trez, D., Caliari, D., Aresu, L. and Castagnaro, M. 2012. Immunohistochemical expression of Ecadherin and $\beta$-catenin in feline mammary tumours. J. Comp. Pathol. 147: 161-170. [Medline] [CrossRef] 